\title{
Kecemasan dan Persepsi Pasien Kanker Ovarium dengan Kemoterapi setelah Terapi Smartphone-Based Virtual Reality (S-VR): Studi Kasus
}

\section{Anxiety and Perception of Ovarian Cancer Patients with Chemotherapy Using Smartphone -Based Virtual Reality (S-VR): A Case Study}

\author{
Made Satya Nugraha Gautama ${ }^{1^{*}}$, Wiwin Lismidiati ${ }^{2}$, Farida Widayati ${ }^{3}$ \\ ${ }^{1}$ Program Studi Ilmu Keperawatan, Fakultas Kedokteran, Kesehatan Masyarakat, dan \\ Keperawatan, Universitas Gadjah Mada \\ ${ }^{2}$ Departemen Keperawatan Anak dan Maternitas, Fakultas Kedokteran, Kesehatan \\ Masyarakat, dan Keperawatan, Universitas Gadjah Mada \\ ${ }^{3}$ Rumah Sakit Umum Pusat Dr. Sardjito Yogyakarta
}

\begin{abstract}
Background: Chemotherapy is a systemic modality for cancer patients and has physical and psychological side effects. Psychological problems usually arise most often when undergoing chemotherapy. Not a few patients feel anxiety and negative perceptions when diagnosed with cancer, undergo surgery, or have an IV inserted to get chemotherapy drugs. Virtual Reality (VR) is a technologybased non-complementary therapy that has the potential to be involved as an alternative in the management of symptoms of cancer patients.

Objective: To describe the effects of using Smartphone-Based Virtual Reality (S-VR) on the level of anxiety and perceptions of cancer patients during chemotherapy.

Methods: A case study of ovarian cancer patient undergoing chemotherapy and were given Smartphone -Based Virtual Reality (S-VR) treatment.

Results: The results obtained were a decrease in situational anxiety facing chemotherapy from a score of 40 (moderate anxiety) to a score of 21 (mild anxiety), decreased in pulse rate, and a significant increase in the perception score (28.6\%) (less perception) to $94.3 \%$ ( good perception) after getting SVR intervention during chemotherapy.

Conclusion: S-VR can be a technology-based and non-invasive non-pharmacological intervention in reducing anxiety and providing positive experiences for patients during chemotherapy.
\end{abstract}

Keywords: anxiety, chemotherapy, perception, virtual reality

\section{ABSTRAK}

Latar Belakang: Tidak sedikit pasien merasakan kecemasan dan persepsi negatif saat didiagnosa kanker, menjalankan pembedahan, atau dipasang infus kemoterapi. Virtual Reality (VR) menjadi salah satu terapi non-komplementer berbasis teknologi yang potensial dilibatkan sebagai alternatif dalam manajemen gejala pasien kanker.

Tujuan: Untuk mengetahui efek penggunaan Smartphone-Based Virtual Reality (S-VR) terhadap tingkat kecemasan dan persepsi pasien kanker selama menjalani kemoterapi.

Metode: Studi kasus dilakukan pada pasien dengan kanker ovarium yang mendapatkan kemoterapi dan diberikan terapi S-VR. Kecemasan diukur dengan instrument S-AI, pengukuran nadi dan RR. Pengukuran persepsi menggunakan instrumen dari Scates.

Hasil: Terjadi penurunan kecemasan saat kemoterapi dari skor 40 (kecemasan sedang) ke skor 21 (kecemasan ringan), penurunan frekuensi nadi dan adanya peningkatan secara signifikan skor persepsi $(65,7 \%)$ (persepsi cukup) menjadi 94,3\% (persepsi baik) setelah mendapatkan intervensi S-VR selama kemoterapi.

Kesimpulan: S-VR dapat menjadi intervensi non-farmakologis berbasis teknologi dan non-invasif dalam menurunkan kecemasan dan memberikan pengalaman positif pada pasien selama menjalani kemoterapi.

Kata Kunci: kanker, kecemasan, kemoterapi, persepsi, virtual reality

Corresponding Author: Made Satya Nugraha Gautama

Jalan Segara, Gang Puri Segara no 5, Banjar, Buleleng, Bali 81152

Email: satyanugraha.g@gmail.com 


\section{PENDAHULUAN}

Kanker ovarium merupakan salah satu penyakit keganasan ginekologi paling sering pada perempuan setelah kanker serviks dan uterus dan menjadi penyebab kematian kedelapan terbesar di seluruh dunia. ${ }^{1}$ Angka kejadian kanker ovarium sebesar 6,1/100.000 wanita per tahun. ${ }^{2}$ Berdasarkan studi Global Ovarian Cancer Rates Rising (FIGO), dilaporkan terdapat 300.000 kasus baru di tahun 2018, dan angkanya akan terus meningkat sebesar 371.000 kasus di tahun 2035 di seluruh dunia. ${ }^{3}$ Tingkat kelangsungan hidup penderita kanker ovarium yang rendah hanya $30-50 \%$ disebabkan terdeteksi dalam stadium menengah hingga lanjut, sehingga memerlukan segera terapi modalitas pada kanker seperti pembedahan, radioterapi dan kemoterapi. ${ }^{4,5}$

Kemoterapi merupakan salah satu modalitas utama pasien kanker dengan tujuan pemberian untuk kuratif, life-extending dan paliatif. ${ }^{6}$ Pengobatan dengan siklus dan interval yang relatif lama selain memberikan efek samping fisik pada pasien, juga berdampak pada masalah psikologi pasien. ${ }^{7}$ Banyak pasien mengeluhkan takut saat menjalani pengobatan. ${ }^{8}$ Tidak sedikit juga pasien merasakan kecemasan saat didiagnosa kanker, menjalankan pembedahan, dan dipasang infus untuk mendapatkan obat kemoterapi. ${ }^{9,10}$ Masalah psikologis pada pasien kanker paling sering diberikan terapi nonfarmakologis, seperti exercise, nafas dalam, dan teknik relaksasi lain. ${ }^{11}$

Di era modern ini, pemanfaatan teknologi untuk terapi non farmakologis menjadi penting dalam mendukung fungsi kognitif, sosial dan emosional pasien kanker. ${ }^{12}$ Salah satu teknologi yang potensial dilibatkan dalam manajemen gejala pasien kanker adalah virtual reality (VR). ${ }^{10,13}$ VR merupakan teknologi berbasis tiga dimensi, non-invasif, yang membuat penggunanya dapat merasakan dan berinteraksi dengan lingkungan yang ada dalam dunia maya. ${ }^{14,15}$ VR sebagai teknik distraksi efektif meredakan nyeri dan kecemasan, memberikan rasa aman dan nyaman pasien kanker selama mendapatkan perawatan di rumah sakit dan selama kemoterapi. ${ }^{16,17,18}$

Di Indonesia, pemanfaatkan teknologi VR masih belum banyak diterapkan pada proses perawatan pasien di rumah sakit. Selain itu, masih sedikit literatur yang melaporkan penggunaan VR untuk meredakan kecemasan dan memberikan pengalaman pada pasien kanker yang mendapatkan kemoterapi. Oleh karena itu, pada studi kasus ini, peneliti mencoba menerapkan metode virtual reality berbasis telepon pintar (S-VR) yang digunakan pada salah satu pasien kanker ovarium di salah satu bangsal rumah sakit di Yogyakarta, Indonesia.

\section{METODE PENELITIAN}

Penelitian ini merupakan sebuah studi kasus dengan melibatkan subjek tunggal. Instrumen digunakan pada kondisi selama pasien mendapatkan kemoterapi sebelum dan setelah mendapatkan intervensi simulasi S-VR. Instrumen State Anxiety Inventory (S-Al) oleh 
Spielberger ${ }^{19}$ digunakan untuk mengukur kecemasan pasien dalam menjalani kemoterapi dan terapi S-VR. Menurut Spielberger, instrumen S-Al digunakan untuk mengetahui tingkat kecemasan situasional seseorang menghadapi kondisi atau masalah tertentu. ${ }^{19} \mathrm{~S}-\mathrm{Al}$ terdiri dari 20 pertanyaan dengan skala likert 1-4 (1 - sama sekali tidak merasakan, 2 - sedikit merasakan, 3 - cukup merasakan, 4 - sangat merasakan). Sebanyak 10 item adalah favorable dan 10 item nonfavorable. Range total skor SAI antara 20-80 dengan pengkategorian skor 60 - 80 dikategorikan kecemasan berat, kecemasan sedang skor 40 - 59, dan kecemasan ringan skor 20 - 39. Peneliti melakukan pengukuran nadi dan respiratory rate pada saat pasien mendapatkan kemoterapi dan terapi S-VR.

Sementara, untuk pengukuran persepsi pasien, peneliti mengadaptasi instrumen persepsi pasien kanker oleh Scates et a.Ro Instrumen persepsi terdiri dari 7 item pertanyaan untuk mengukur persepsi pasien yang menjalani kemoterapi dengan mendapatkan terapi S-VR. Item pertanyaan menggunakan jawaban skala likert 1-5 ( 1 = sangat tidak setuju; $2=$ tidak setuju; $3=$ ragu - ragu; $4=$ setuju dan $5=$ sangat setuju). Dilakukan konversi penilaian persepsi partisipan menjadi skor persentase. Skor persentase dihitung dengan membagi total skor instrumen yang telah diisi oleh partisipan dengan total skor maksimal instrumen lalu dikalikan $100 \%$. Penulis menetapkan kategorisasi persepsi menjadi 3 kelompok berdasarkan total skor persentase dengan pengkategorian skor $20 \%$ - $40 \%$ dikategorikan persepsi kurang, skor $50 \%-70 \%$ persepsi cukup, dan persepsi baik dengan skor 80\%-100\%. Satu pertanyaan terbuka digunakan di bagian post kuesioner persepsi untuk menggali secara kualitatif pengalaman pasien mendapatkan S-VR.

Karakteristik partisipan ditentukan dengan kriteria inklusi masih menjalani kemoterapi ke1 sampai ke-2, skrining kecemasan awal menunjukkan tingkat sedang hingga berat, fungsi penglihatan dan pendengaran baik, dan bersedia menjadi partisipan studi kasus. Pasien akan dieksklusi ketika memiliki fungsi activity daily living (ADL) bergantung total, sedang dalam perbaikan keadaan umum, dan tidak mendapatkan regimen kemoterapi.

Seorang pasien, perempuan, berusia 22 tahun didiagnosa kanker ovarium, post salpingoooforektomi (USO). Pasien rencana mendapatkan kemoterapi siklus ke-2 dari total 5 siklus dengan interval 3 minggu, berupa BEP (Bleomysin 15 mg - Etoposide 80 mg - Cisplatin 100 $\mathrm{mg}$ ) secara intravena. Durasi pemberian BEP memakan waktu \pm 3 jam. Hasil pemeriksaan fisik pasien meliputi berat badan 63,4 kg; tinggi badan $155 \mathrm{~cm}$; IMT 26,39 kg/m²; tekanan darah $110 / 70 \mathrm{mmHg}$; suhu tubuh $36,3^{\circ} \mathrm{C}$; denyut nadi $90 \mathrm{x} /$ menit; frekuensi nafas $20 \mathrm{x} /$ menit. Fungsi ADL (activity daily living) mandiri, penglihatan normal, pendengaran normal, tidak ada risiko jatuh, terpasang IV-line dengan $\mathrm{NaCl} 500 \mathrm{ml}$ di tangan kiri.

Pasien dilibatkan pada eksperimen kasus ini untuk kondisi pre-post penggunaan S-VR selama kemoterapi berlangsung. Langkah awal, pasien diminta menjawab 2 kuesioner terkait kecemasan dan persepsi pasien sebelum kemoterapi. Setelah pasien menyelesaikan 
pengisian kuesioner, peneliti melanjutkan pemberikan obat kemoterapi Bleomycin $50 \mathrm{mg}$ dalam $250 \mathrm{ml} \mathrm{NaCL}$ secara drip infus. Peneliti memastikan kepatenan akses vena baik dan tidak ada keluhan terkait efek samping obat. Setelah itu, peneliti memasangkan kacamata VR yang sudah terpasang telepon pintar dan headset (Gambar 1).

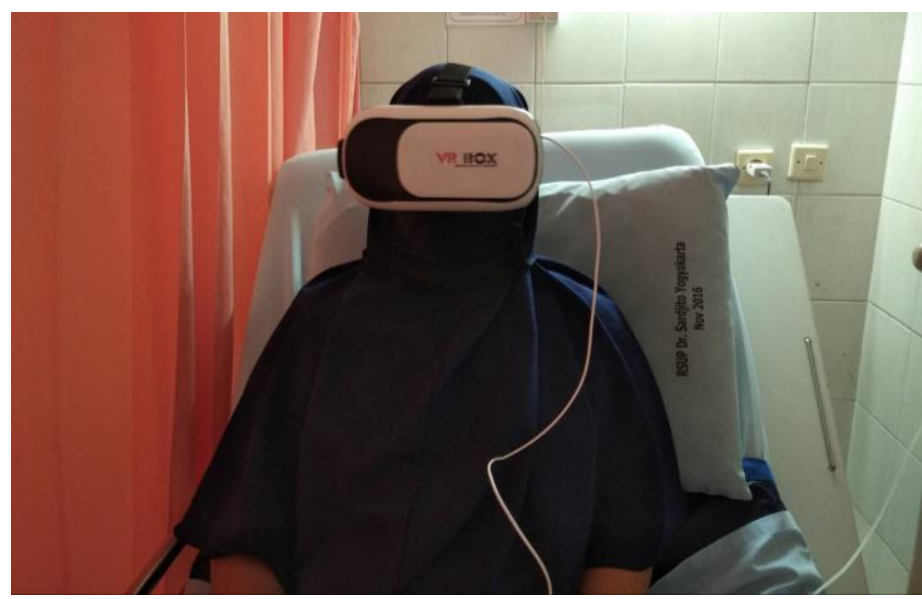

Gambar 1. Pasien menggunakan Kacamata VR

Video simulasi yang ditayangkan dari S-VR ini menampilkan simulasi video $360^{\circ}$ dengan panorama alam berlatar musik relaksasi dan berdurasi 6 menit 10 detik. Pasien diminta menoleh kiri, kanan, atas dan bawah untuk merasakan suasana kenyataan panorama alam di dunia maya (Gambar 2 dan Gambar 3).

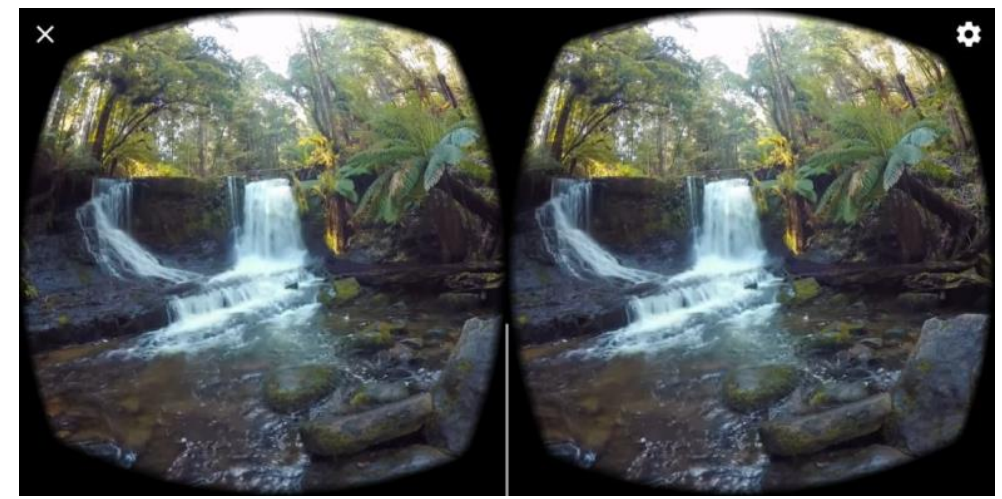

Gambar 2. Tampilan video simulasi saat menggunakan VR

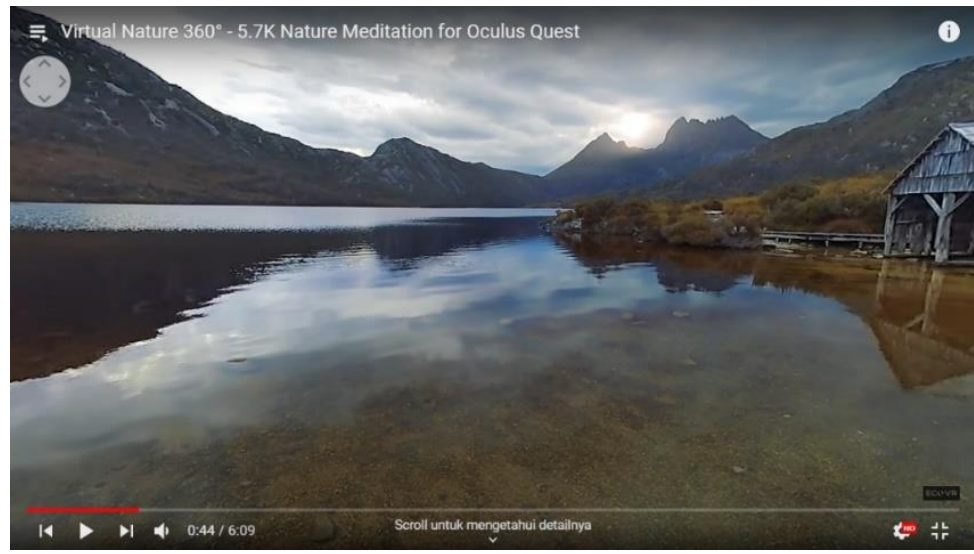

Gambar 3 . Tampilan video simulasi VR 
Pasien diharapkan melaporkan kesulitan atau rasa tidak nyaman selama menggunakan kacamata VR ini. Segera setelah video simulasi berakhir, kacamata VR dilepas beserta headset, kemudian meminta pasien mengisi lembar post-test kuesioner yang sudah disediakan.

\section{HASIL}

Hasil menunjukkan pengukuran skor kecemasan pada tahap sebelum diberikan intervensi S-VR yaitu 40, artinya pasien berada pada kategori kecemasan sedang saat akan menjalankan kemoterapi. Kemudian, setelah pasien memperoleh intervensi S-VR, penurunan signifikan ditunjukkan pada skor pengukuran kecemasan, yaitu 21 (Gambar 4). Skor ini menunjukkan bahwa pasien berada pada kategori kecemasan ringan.

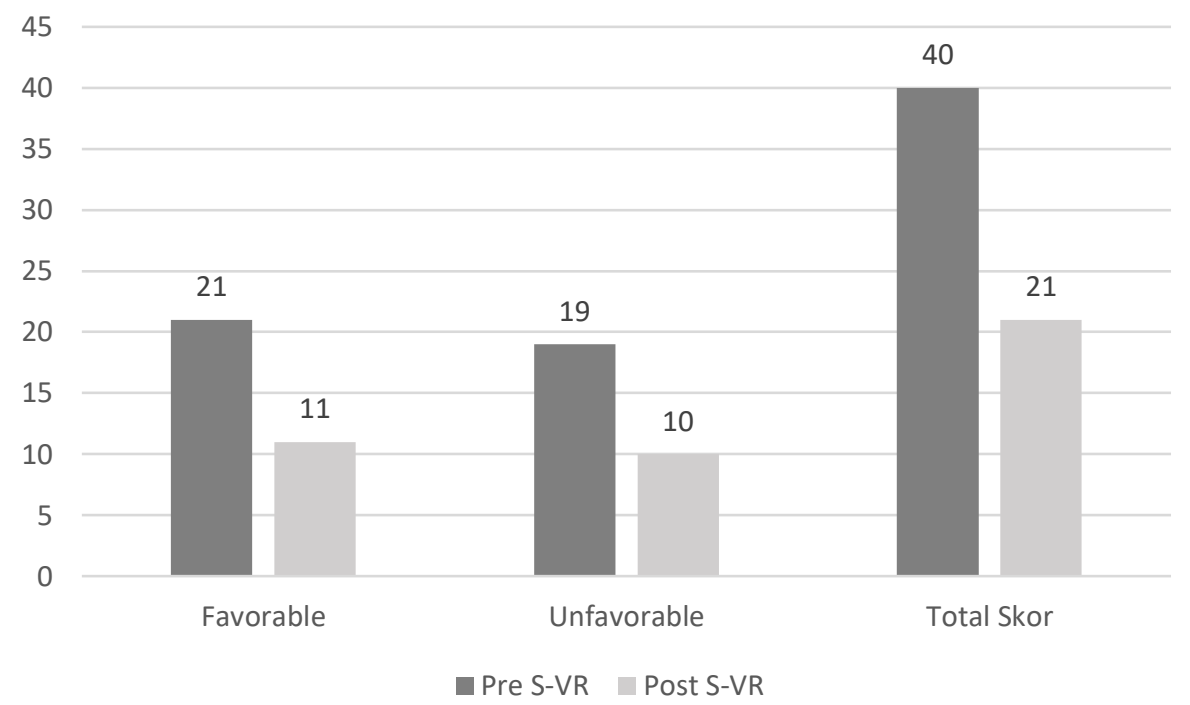

Gambar 4. Tingkat kecemasan pasien

Pemantauan frekuensi nadi dan pernapasan dilakukan sebelum, selama, dan setelah penggunaan S-VR pada pasien yang menerima kemoterapi. Hasil pemantauan ditampilkan pada gambar di bawah ini.

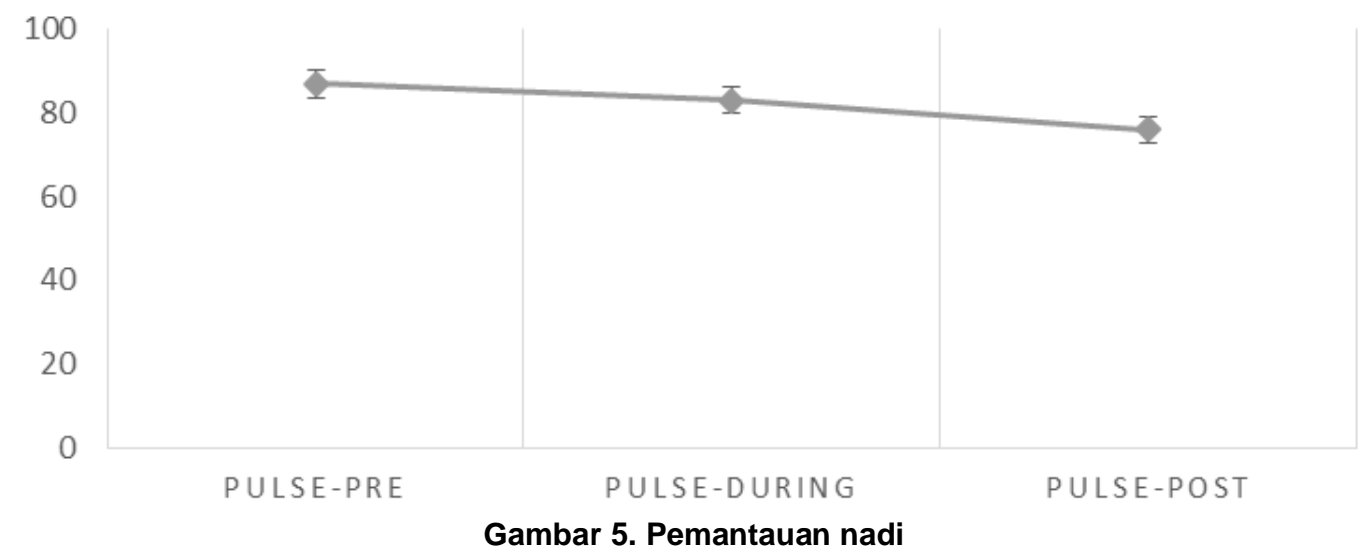




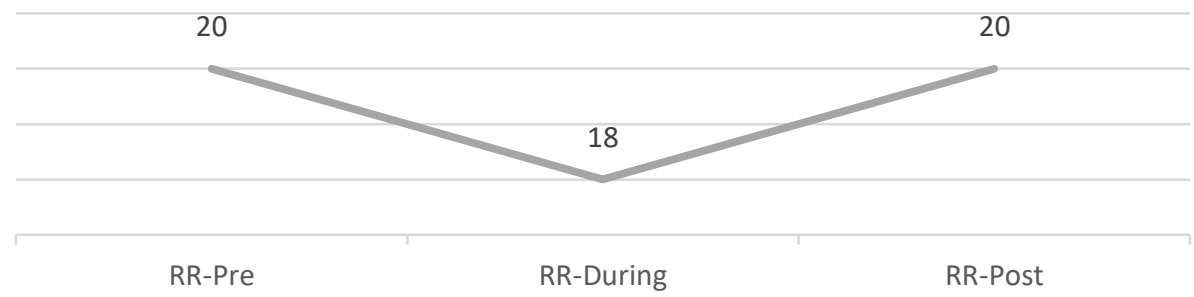

Gambar 6. Pemantauan frekuensi nafas

Hasil pemantauan nadi menunjukkan adanya penurunan frekuensi nadi pasien secara bertahap, dari sebelum kemoterapi dimulai, selama kemoterapi dan penggunaan S-VR hingga setelah intervensi. Sementara, pada pemantauan frekuensi nafas, menunjukkan frekuensi nafas pasien dalam batas normal, tidak ada perubahan yang signifikan sebelum hingga setelah intervensi.

Tabel 1. Pengukuran persepsi pasien kanker ovarium pre-post SVR

\begin{tabular}{lcc}
\hline Pernyataan & Pre S-VR & Post S-VR \\
\hline Hari ini saya memperoleh pengalaman menarik dalam mengikuti prosedur ini & 4 & 5 \\
Prosedur yang saya jalani tidak membuat saya takut & 2 & 5 \\
Prosedur yang saya jalani tidak membuat saya kecewa & 3 & 5 \\
Saya merasa terdistraksi/teralihkan selama saya menjalani prosedur ini & 2 & 4 \\
Saya merasa rileks selama saya menjalankan prosedur ini & 4 & 5 \\
Saya merasa nyaman selama menjalani prosedur ini & 4 & 4 \\
Saya merasa tidak nyeri/sakit selama menjalani prosedur & 4 & 5 \\
\hline Skor total & 23 & 33 \\
\hline Presentase & $65,7 \%$ & $94,3 \%$ \\
\hline Presentase peningkatan skor & \multicolumn{2}{c}{$28,6 \%$} \\
\hline
\end{tabular}

Berdasarkan Tabel 1 diatas, diperoleh gambaran persepsi pasien kanker ovarium yang menerima kemoterapi sebelum menggunakan S-VR sebesar $65,7 \%$ yang menunjukkan persepsi cukup dalam menjalankan kemoterapi. Sementara, hasil positif ditunjukkan dengan adanya peningkatan signifikan skor persepsi $(28,6 \%)$ setelah mendapatkan intervensi S-VR dalam menjalankan kemoterapi menjadi $94,3 \%$. Hasil ini menunjukkan bahwa persepsi pasien yang menjalani kemoterapi dengan S-VR adalah baik. Pada kuesioner post-test, disediakan satu pertanyaan terbuka tentang persepsi pasien terhadap penggunaan S-VR selama menjalani kemoterapi. Pertanyaannya adalah "Apakah yang Anda rasakan setelah menggunakan alat ini?", jawaban dari pasien berbunyi "Setelah saya menggunakan alat ini, yang saya rasakan adalah perasaan tegang dan khawatir dalam diri saya menjadi tidak ada. Selain itu, alat ini juga membuat saya menjadi lebih tenang."

\section{PEMBAHASAN}

Saat ini belum ada studi kasus yang melaporkan penerapan S-VR sebagai salah satu terapi non-farmakologis berbasis teknologi dalam meredakan kecemasan dan memberikan pengalaman baru pada pasien kanker yang menjalani kemoterapi. Luaran yang diperoleh dari studi kasus ini menunjukkan hasil yang positif. Manfaat utama penggunaan S-VR pada pasien 
dalam menjalani kemoterapi ditunjukkan dari penurunan tingkat kecemasan pasien dari kategori kecemasan sedang ke kecemasan ringan. Hasil positif ini sejalan dengan penelitian Chirico et $a^{R 1}$ tentang penggunaan VR dibandingkan dengan terapi musik pada pasien kanker payudara selama menjalani kemoterapi. Studi ini melaporkan, VR efektif mengurangi kecemasan dan memperbaiki suasana hati pasien kanker selama kemoterapi. Terapi ini juga dapat menurunkan kecemasan dan mendistraksi saat pemasangan jalur intravena perifer pada pasien anak - anak dengan kanker yang menerima kemoterapi. ${ }^{21,22}$

Sebuah studi tahun 2018 yang menggunakan EEG (Electroencephalography) untuk merekam aktivitas otak partisipan melaporkan bahwa VR dapat digunakan sebagai intervensi yang dapat menurunkan kecemasan. Secara fisiologis akan terjadi perubahan aktivitas gelombang otak manusia dari awalnya frekuensi gelombang beta menjadi frekuensi gelombang alpa. Gelombang beta yang tinggi dikaitkan dengan keadaan cemas dan stres. Sementara peningkatan frekuensi gelombang alpa atau penurunan gelombang beta dikaitkan dengan keadaan relaksasi dan tenang. ${ }^{23}$ Perubahan frekuensi ini secara spesifik terjadi di prefrontal korteks otak di bagian anterior cingulate atau midline cortex. ${ }^{24}$

Adapun hasil yang menarik yang diperoleh studi kasus ini terkait penilaian persepsi pasien menerima terapi S-VR. Persepsi baik ditunjukkan pasien setelah menggunakan S-VR dengan beberapa indikator antara lain: pengalaman, rasa takut, rasa kecewa, distraksi, rasa nyaman dan nyeri sebelum dan setelah terapi. Data kuantitatif ini didukung juga dari jawaban pertanyaan terbuka yang dibuat, bahwa pasien menyatakan pengalaman pertama kali menggunakan S-VR membuat rasa khawatir dan tegang dapat mereda, serta memberikan ketenangan selama kemoterapi. Sejalan dengan penelitian lain, pasien merasakan penggunaan VR ini dapat mendistraksi rasa nyeri saat dipasang akses intravena sebelum kemoterapi. ${ }^{17,25}$ Pengalaman berharga, tenang, damai dan rileks dirasakan ketika VR menampilkan simulasi video panorama dengan suara - suara alam yang menenangkan..$^{21,26}$ VR juga digunakan sebagai salah satu modalitas terapeutik untuk manajemen gejala, rehabilitasi dan dukungan psikologi pada pasien paliatif. ${ }^{27}$

\section{KESIMPULAN DAN SARAN}

Studi kasus ini melaporkan tingkat kecemasan pasien dengan kanker ovarium setelah melalui terapi Smartphone-Based Virtual Reality ( $S-V R$ ) berada pada kategori ringan dari sebelumnya pada kategori sedang. Sementara persepsi baik ditunjukkan pasien selama menjalani kemoterapi dan S-VR. Terapi non-farmakologis ini dapat digunakan sebagai salah satu alternatif intervensi keperawatan terapeutik berbasis teknologi yang mudah, aplikatif dan non-invasif pada pasien kanker dalam mengatasi masalah fisik maupun psikologis yang muncul selama menjalani kemoterapi. Diharapkan, studi kasus ini dapat dilanjutkan tingkat 
penelitian lebih tinggi maupun pengembangan intervensi sehingga memperoleh hasil yang optimal.

\section{UCAPAN TERIMAKASIH}

Ucapan terima kasih peneliti sampaikan kepada responden penelitian dan semua pihak yang telah membantu dalam penelitian ini.

\section{DAFTAR PUSTAKA}

1. Torre LA, Bray F, Siegel RL, Ferlay J, Lortet-Tieulent J, Jemal A. Global cancer statistics, 2012. CA: a cancer journal for clinicians. 2015 Mar;65(2):87-108.

2. Bray F, Ferlay J, Soerjomataram I, Siegel RL, Torre LA, Jemal A. Global cancer statistics 2018: GLOBOCAN estimates of incidence and mortality worldwide for 36 cancers in 185 countries. CA: a cancer journal for clinicians. 2018 Nov;68(6):394-424.

3. Bhatla N, Denny L. FIGO cancer report 2018. International Journal of Gynecology \& Obstetrics. 2018 Oct;143:2-3.

4. Harsono AB. Kanker Ovarium: “The Silent Killer”. Indonesian Journal of Obstetrics \& Gynecology Science. 2020 Mar 29;3(1):1-6.

5. Chandra A, Pius C, Nabeel M, Nair M, Vishwanatha JK, Ahmad S, Basha R. Ovarian cancer: Current status and strategies for improving therapeutic outcomes. Cancer medicine. 2019 Nov;8(16):7018-31.

6. Neugut Al, Prigerson HG. Curative, Life-Extending, and Palliative Chemotherapy: New Outcomes Need New Names. The oncologist. 2017 Aug;22(8):883.

7. Oh PJ, Cho JR. Changes in fatigue, psychological distress, and quality of life after chemotherapy in women with breast cancer: a prospective study. Cancer nursing. 2020 Jan 1;43(1):E54-60.

8. American Cancer Society. Anxiety, fear, and depression. Having cancer affects your emotional health. Available from:https://www.cancer.org/treatment/treatmentsand-side-effects/emotionalside-effects/anxiety-fear-depression.html [Access 4th October 2020]

9. Chandwani KD, Ryan JL, Peppone LJ, Janelsins MM, Sprod LK, Devine K, Trevino L, Gewandter J, Morrow GR, Mustian KM. Cancer-related stress and complementary and alternative medicine: a review. Evidence-Based Complementary and Alternative Medicine. 2012 Jan 1;2012.

10. Chirico A, Lucidi F, De Laurentiis M, Milanese C, Napoli A, Giordano A. Virtual reality in health system: beyond entertainment. a mini-review on the efficacy of VR during cancer treatment. Journal of cellular physiology. 2016 Feb;231(2):275-87.

11. Duncan M, Moschopoulou E, Herrington E, Deane J, Roylance R, Jones L, Bourke L, Morgan A, Chalder T, Thaha MA, Taylor SC. Review of systematic reviews of non-pharmacological interventions to improve quality of life in cancer survivors. BMJ open. 2017 Nov 1;7(11).

12. Cherry B, Jacob SR. Contemporary nursing: Issues, trends, \& management. Elsevier Health Sciences; 2016 Feb 1.

13. Baños RM, Espinoza M, García-Palacios A, Cervera JM, Esquerdo G, Barrajón E, Botella C. A positive psychological intervention using virtual reality for patients with advanced cancer in a hospital setting: a pilot study to assess feasibility. Supportive Care in Cancer. 2013 Jan 1;21(1):263-70.

14. Dos Santos JR, Werner H, Ribeiro G, Belmonte SL. Combination of non invasive medical imaging technologies and virtual reality systems to generate immersive fetal $3 \mathrm{D}$ visualizations. InInternational Conference on Digital Human Modeling and Applications in Health, Safety, Ergonomics and Risk Management 2016 Jul 17 (pp. 92-99). Springer, Cham.

15. Parong J, Mayer RE. Learning science in immersive virtual reality. Journal of Educational Psychology. 2018 Aug;110(6):785.

16. Jimenez YA, Cumming S, Wang W, Stuart K, Thwaites DI, Lewis SJ. Patient education using virtual reality increases knowledge and positive experience for breast cancer patients undergoing radiation therapy. Supportive Care in Cancer. 2018 Aug 1;26(8):2879-88.

17. Mohammad EB, Ahmad M. Virtual reality as a distraction technique for pain and anxiety among patients with breast cancer: A randomized control trial. Palliative \& supportive care. 2019 Feb;17(1):29-34.

18. Garrett BM, Tao G, Taverner T, Cordingley E, Sun C. Patients perceptions of virtual reality therapy in the management of chronic cancer pain. Heliyon. 2020 May 1;6(5):e03916. 
19. Hoellen F, Wagner JF, Lüdders DW, Rody A, Banz-Jansen C. Anxiety in caregiving partners of breast cancer patients. Archives of gynecology and obstetrics. 2019 Oct 1;300(4):993-1005.

20. Scates D, Dickinson JI, Sullivan K, Cline H, Balaraman R. Using Nature-Inspired Virtual Reality as a Distraction to Reduce Stress and Pain Among Cancer Patients. Environment and Behavior. 2020 May 22:0013916520916259.

21. Chirico A, Maiorano $P$, Indovina $P$, Milanese $C$, Giordano $G G$, Alivernini $F$, lodice $G$, Gallo L, De Pietro G, Lucidi F, Botti G. Virtual reality and music therapy as distraction interventions to alleviate anxiety and improve mood states in breast cancer patients during chemotherapy. Journal of Cellular Physiology. 2020 Jun;235(6):5353-62.

22. Wong CL, Li CK, Chan CW, Choi KC, Chen J, Yeung MT, Chan ON. Virtual Reality Intervention Targeting Pain and Anxiety Among Pediatric Cancer Patients Undergoing Peripheral Intravenous Cannulation: A Randomized Controlled Trial. Cancer Nursing. 2020 Jun 4.

23. Tarrant J, Viczko J, Cope H. Virtual reality for anxiety reduction demonstrated by quantitative EEG: a pilot study. Frontiers in psychology. $2018 \mathrm{Jul} \mathrm{24;} \mathrm{9:1280.} \mathrm{10.3389/fpsyg.2018.01280}$

24. Sherlin L, Muench F, Wyckoff $S$. Respiratory sinus arrhythmia feedback in a stressed population exposed to a brief stressor demonstrated by quantitative EEG and sLORETA. Applied Psychophysiology and Biofeedback. 2010 Sep 1;35(3):219-28. https://doi.org/10.1007/s10484010-9132-z

25. Tashjian VC, Mosadeghi S, Howard AR, Lopez M, Dupuy T, Reid M, Martinez B, Ahmed S, Dailey F, Robbins K, Rosen B. Virtual reality for management of pain in hospitalized patients: results of a controlled trial. JMIR mental health. 2017;4(1):e9.

26. Tanja-Dijkstra K, Pahl S, White MP, Auvray M, Stone RJ, Andrade J, May J, Mills I, Moles DR. The soothing sea: a virtual coastal walk can reduce experienced and recollected pain. Environment and behavior. $2018 \mathrm{Jul} ; 50(6): 599-625$.

27. Johnson T, Bauler L, Vos D, Hifko A, Garg P, Ahmed M, Raphelson M. Virtual reality use for symptom management in palliative care: a pilot study to assess user perceptions. Journal of Palliative Medicine. 2020 Jan 2. 